\title{
New Alternative to Produce Colored Polymer Nanocomposites: Organophilic Ni/Al and Co/Al Layered Double Hydroxide as Fillers into Low-Density Polyethylene
}

\author{
Silvia Jaerger, ${ }^{a}$ Sonia F. Zawadzki, ${ }^{a}$ Andreas Leuteritz ${ }^{b}$ and Fernando Wypych ${ }^{*, a}$ \\ ${ }^{a}$ Centro de Pesquisas em Química Aplicada (CEPESQ), Departamento de Química, \\ Universidade Federal do Paraná (UFPR), CP 19032, 81531-980 Curitiba-PR, Brazil
}

${ }^{b}$ Leibniz-Institut für Polymerforschung Dresden e.V., Hohe Str. 6, 01069 Dresden, Germany

\begin{abstract}
Green $\left(\mathrm{Ni}^{2+} / \mathrm{Al}^{3+}\right)$ and pink $\left(\mathrm{Co}^{2+} / \mathrm{Al}^{3+}\right)$ layered double hydroxides (LDH) (molar ratio of 3:1) were intercalated with several organic anions and used as functional colored fillers into low density polyethylene (LDPE) by melt mixing in amounts of 0.2 to $7 \mathrm{wt}$ \%. Scanning electron microscopic (SEM) results of LDPE nanocomposites indicated that with low percentage of filler, all the LDH samples showed efficient delamination/exfoliation in the polymer matrix. Fillers added to LDPE with concentrations of $0.2,0.5,2$ and $5 \%$ presented, in general, maintenance of Young's modulus and tensile strength, tending to the reduction with a loading of $7 \%$. Most of the nanocomposites presented similar elongations, although NiUS stood out, with an elongation increase of $300 \%$. Differential scanning calorimetry (DSC) indicated the effect of the Co/Al-LDH in inducing the formation of LDPE crystalline domains, especially at higher temperature than neat LDPE.
\end{abstract}

Keywords: colored layered double hydroxides, polymer-matrix composites, intercalation

\section{Introduction}

Research and development of new structural materials with good mechanical performance combined with additional functional properties are great scientific challenges for the $21^{\text {st }}$ century, ${ }^{1}$ and nanocomposites are anticipated to be among the solutions in this respect. Polymer nanocomposites constitute a class of hybrid materials formed from organic and inorganic compounds, which have the inorganic phase dispersed in the form of nanometric particles in a polymeric matrix. The Toyota Research Laboratory in Japan first studied this class of materials in the 1990s, leading to the development of polymer nanocomposites based on polyamide and 2:1 clay minerals. ${ }^{2-4}$

Important characteristics such as high strength and toughness, light weight and other properties make polymer nanocomposites ideal for engineering applications, ranging from biomedical devices to packaging. ${ }^{5-9}$ On other hand, the cost can be greatly reduced by precise selection of functional fillers and the polymer. ${ }^{5}$

Even after 25 years of research, most studies of layered minerals for polymer nanocomposites have been focused

*e-mail: wypych@ufpr.br on natural materials, such as clay minerals, with cation exchange capacity. These materials have advantages and disadvantages: the main disadvantages are the materials' chemical composition, cation exchange capacity, fixed crystal morphology and content of impurities, which are greatly affected by the genesis and even mining location. Synthetic layered materials, such as layered double hydroxides (LDHs) and layered hydroxide salts (LHSs), do not have the disadvantages of clay minerals. Therefore, these compounds are the most suitable for application as fillers for polymer nanocomposites..$^{7-15}$ However, research articles about polymer nanocomposites based on polyolefin and layered double hydroxides are still relatively scarce. ${ }^{16}$

Layered compounds are characterized by stacked layers (having thickness from one to several atoms), in which the atoms have strong bonds along the crystallographic axes $\mathrm{a}$ and $\mathrm{b}$, and are stacked along the c-axis (basal axis). ${ }^{17,18}$ The LDH structures are considered to be based on the brucite-like structure $\left(\mathrm{M}(\mathrm{OH})_{2}\right),{ }^{19,20}$ which belongs to a group of simple hydroxides, common to magnesium, calcium, manganese(II), iron(II), cobalt(II) and nickel(II) hydroxides. Some of the divalent layer ions are substituted by trivalent ions, thus introducing a net positive charge in the layer. This positive charge is counter balanced by 
anions in the interlayer region. $\mathrm{LDH}$ can be represented by the general formula $\left[\mathrm{M}^{+2}{ }_{1-x} \mathrm{M}^{+3}{ }_{x}(\mathrm{OH})_{2}\right]^{\mathrm{x}}\left(\mathrm{A}^{\mathrm{n}-}\right)_{\mathrm{x} / \mathrm{n}} \cdot \mathrm{yH}_{2} \mathrm{O}$, with very interesting variable characteristics. The divalent metal ions can vary from $\mathrm{Mg}^{2+}, \mathrm{Ni}^{2+}, \mathrm{Zn}^{2+}, \mathrm{Ca}^{2+}, \mathrm{Co}^{2+}$ and $\mathrm{Cu}^{2+}$ to many other cations, and the trivalent metal can be $\mathrm{Al}^{3+}, \mathrm{Fe}^{3+}, \mathrm{Cr}^{3+}, \mathrm{Ga}^{3+}$ or $\mathrm{In}^{3+}$. Common counter ions can be $\mathrm{CO}_{3}{ }^{2-}, \mathrm{NO}_{3}-$ or $\mathrm{Cl}^{-}$, or organic anions such as dodecylsulfate, laurate and other long alkyl chain carboxylates, sulfonate and phosphonates. ${ }^{18,21}$

In order to obtain a homogeneous dispersion of individual LDH layers in a polymer matrix, it is desirable to use LDH intercalated with organic anions. These anions make the filler more compatible with the polymer and thus facilitate the penetration of the polymer chains. Ideally, such organophilic fillers exfoliate, accompanied by a dramatic increase of surface area, changing many properties of the nanocomposites. ${ }^{16}$

When one talks about colored nanocomposites, many obstacles can be taken into account as often when dyes or pigments are added, it can cause degradation changing polymer properties and promote dye salts migration and exudation to the environment due to the low chemical affinity with the polymer. One advantage is the possibility of producing colored polymers by the intercalation of anionic dyes into layered materials avoiding migration and exudation, ${ }^{22-24}$ the use of colored cations in the layer composition as pigments or even both alternatives. Although there are advantages to use multifunctional filler having also the capacity to attribute color to the polymer, according to the authors knowledge, the last two alternatives were never reported in the literature.

Thus, in this study, colored layered double hydroxides were prepared with the combination of $\mathrm{Ni} / \mathrm{Al}$ and $\mathrm{Co} / \mathrm{Al}$ intercalated with different organic anions. Once synthesized, the layered materials were characterized by instrumental techniques and used as fillers for low-density polyethylene (LDPE) nanocomposites, where the thermal stability, mechanical and other properties were evaluated.

\section{Experimental}

The reagents $\mathrm{Ni}\left(\mathrm{NO}_{3}\right)_{2} \cdot 6 \mathrm{H}_{2} \mathrm{O}, \mathrm{Co}\left(\mathrm{NO}_{3}\right)_{2} \cdot 6 \mathrm{H}_{2} \mathrm{O}$ and $\mathrm{Al}\left(\mathrm{NO}_{3}\right)_{3} \cdot 6 \mathrm{H}_{2} \mathrm{O}$ used in the synthesis of layered compounds were of analytical grade and supplied by Vetec (Brazil). Sodium dodecylsulfate (NaDDS) was obtained from Synth (Brazil). Lauric, palmitic and stearic acids and urea were supplied by Sigma-Aldrich (Brazil). The low-density polyethylene, PB608 (fluency index $=30 \mathrm{~g} / 10 \mathrm{~min}$ by D1230 ASTM method, density $=0.915 \mathrm{~g} \mathrm{~cm}^{-3}$ by D1505 ASTM method) is a resin free of additive and was kindly donated by Braskem (Brazil).
A solution $(100 \mathrm{~mL})$ containing the metals $\mathrm{M}^{+2}$ $(0.120 \mathrm{~mol}), \mathrm{M}^{+3}(0.040 \mathrm{~mol})$ and urea $(0.120 \mathrm{~mol})$ was heated under reflux for $24 \mathrm{~h}$. Then the green and pink products were separated by centrifugation, repeatedly washed with distilled water and dried in a vacuum oven at $60{ }^{\circ} \mathrm{C}$ for a period of $48 \mathrm{~h}$ ( $\mathrm{NiU}$ and $\mathrm{CoU}$ ).

Before the intercalation of organic anions, the LDH should be free of the anion carbonate, because this is not an easily exchangeable ion and will probably contaminate the final product. The decarbonation process occurred with the addition of $3 \mathrm{~g}$ of LDH in $200 \mathrm{~mL}$ of an acetate buffer solution containing $\mathrm{NaCl}^{25}$ This solution was stirred for a period of $24 \mathrm{~h}$. The buffer solution containing acetic acid, sodium chloride and sodium acetate in the molar ratio 1:9:250 was prepared with distilled water. The solids were separated by centrifugation, repeatedly washed with distilled water and dried in a vacuum oven at $60{ }^{\circ} \mathrm{C}$ for $48 \mathrm{~h}$. This process replaced the carbonate ions of LDHs with chloride anions (NiUC and CoUC).

A solution $\left(100 \mathrm{~mL}, 0.8 \mathrm{~mol} \mathrm{~L}^{-1}\right)$ was prepared by dissolving sodium dodecylsulfate in decarbonated distilled water, using a molar excess of about five times in relation to the intercalated chloride anions to guarantee total exchange. After solubilization of the salt, around $3 \mathrm{~g}$ of the LDH NiUC and CoUC were separately added in the solution and the dispersion was stirred at $100 \mathrm{rpm}$ for $24 \mathrm{~h}$. After that, the products were separated by centrifugation, repeatedly washed with distilled water and dried in a vacuum oven at $60{ }^{\circ} \mathrm{C}$ for $48 \mathrm{~h}$ (NiUD and CoUD).

The anions laurate, palmitate and stearate were obtained from reactions of the respective sodium salts obtained by reacting the acids with $\mathrm{NaOH}$. For this, $80 \mathrm{mmol}$ of acid was dissolved in $300 \mathrm{~mL}$ of methanol and neutralized with a stoichiometric amount of a methanol solution of sodium hydroxide, previously prepared by heating at $50^{\circ} \mathrm{C}$. Sodium laurate was dissolved by adding $400 \mathrm{~mL}$ of water at room temperature while palmitate and stearate sodium salts were solubilized in $400 \mathrm{~mL}$ of $50 \% \mathrm{v} / \mathrm{v}$ methanol/ water solution at $60{ }^{\circ} \mathrm{C}$. Soon after solubilization of the salts, about $3 \mathrm{~g}$ of LDH NiUC and CoUC were added to the solutions, which remained under magnetic stirring for $48 \mathrm{~h}$ (the excess was also of about five times). Finally, the products, labeled NiUL, NiUP, NiUS, CoUL, CoUP and CoUS, were separated by centrifugation. The products containing palmitate and stearate were washed with hot distilled water and the others at room temperature. All the compounds were dried in a vacuum oven at $60^{\circ} \mathrm{C}$ for $48 \mathrm{~h}$.

Layered materials previously prepared with different percentages in relation to the LDPE mass $(0.2,0.5$, $2.0,5$ and $7 \% \mathrm{~m} / \mathrm{m}$ ) were used to feed the extruder. Ten specimens were prepared of each composition by 
melting the LDPE/filler mixtures in a Haake MINILAB II micro-extruder at $160 \mathrm{bar}, 130^{\circ} \mathrm{C}$ and $5 \mathrm{~min}$. The material was then injected at 320 bar into a mold cavity $\left(\right.$ at $40{ }^{\circ} \mathrm{C}$ ) to produce ASTM D638 samples (type IV) in a Haake Minijet II injector. For statistical purposes, 10 specimens were evaluated for each composition and average values are presented, excluding outliers.

$\mathrm{X}$-ray diffraction (XRD) analysis was performed using a Shimadzu 6000 diffractometer, with $\mathrm{Cu} \mathrm{K} \alpha$ radiation ( $\lambda=1.5418 \AA$ ), operating at $30 \mathrm{~mA}$ and $40 \mathrm{kV}$. Samples were placed on glass holders and gently adjusted to the surface to avoid displacement errors.

Fourier transform infrared (FTIR) spectra were obtained with a spectrophotometer, Varian 660 configured for working in the IR region (4500-400 $\left.\mathrm{cm}^{-1}\right)$, using $\mathrm{KBr}$ pellets with accumulation of 32 scans and resolution of $4 \mathrm{~cm}^{-1}$. Wide angle X-ray diffraction (WAXS) patterns were measured in the region from 0.5 to $50^{\circ}$ (in $2 \theta$ ), using steps of 0.1 to $0.02^{\circ}$, with a Bruker AXS diffractometer. The patterns were obtained using $\mathrm{Cu} \mathrm{K} \alpha$ radiation ( $\lambda=1.5418 \AA$ ), operating at $30 \mathrm{~mA}$ and $40 \mathrm{kV}$. The diameter of the primary pinhole was set to $0.5 \mathrm{~mm}$ (with a distance of $12 \mathrm{~cm}$ from the detector) and the measurement time was set at $600 \mathrm{~s}$. Thermal analyses (thermogravimetric analysis/ derivative thermogravimetric analysis (TGA/DTG)) were performed with the PerkinElmer TGA, under nitrogen flow, between 40 and $800{ }^{\circ} \mathrm{C}$ at a heating rate of $10{ }^{\circ} \mathrm{C} \mathrm{min}{ }^{-1}$. For the LDH, only the TGA measurements were obtained, while for the nanocomposites both analyses were performed. Differential scanning calorimetry (DSC) analysis of the unfilled and filled polymers was performed with a NETZSCH DSC 200 equipment under nitrogen atmosphere using the following running cycle: heating from room temperature to $180^{\circ} \mathrm{C}\left(\right.$ at $\left.10^{\circ} \mathrm{C} \mathrm{min}^{-1}\right)$, stabilized for 5 min at $150{ }^{\circ} \mathrm{C}$, cooling to $-80{ }^{\circ} \mathrm{C}$ (at $10^{\circ} \mathrm{C} \mathrm{min}^{-1}$ ), and heating up to $150^{\circ} \mathrm{C}\left(\right.$ at $\left.10^{\circ} \mathrm{C} \mathrm{min}{ }^{-1}\right)$. Only the first cooling and second heating curves were registered. Tensile testing was carried out in a universal testing machine Instron 5567, equipped with $1 \mathrm{kN}$ load cell. For each family of samples, ten specimens were evaluated at a speed of $10 \mathrm{~mm} \mathrm{~min}^{-1}$ and a minimum of five results were used to calculate the mean values. The scanning electron microscopy (SEM) images of the cryogenic fracture were recorded on a Tescan VEGA3 LMU microscope at $10 \mathrm{kV}$.

\section{Results and Discussion}

The urea method was used to ensure control and reproducibility as well as to improve the materials' crystallinity. This method replaces the $\mathrm{NaOH}$ by hydrolyzed urea as precipitant. The big advantage of this procedure is that the hydrolysis of urea occurs slowly and promotes a low degree of saturation in $\mathrm{LDH}$ precipitation, increasing the $\mathrm{LDH}$ crystals size. At temperatures above $60^{\circ} \mathrm{C}$, the urea undergoes hydrolysis, releasing ammonia, which assures the necessary alkaline condition for the precipitation. ${ }^{26}$ LDH containing carbonate as the counterion prepared by this method exhibits homogeneous size with well-defined hexagonal morphology and generally good crystallinity. Urea is a weak Brönsted base with $\mathrm{pK}_{\mathrm{b}}=13.8$, very soluble in water, and its hydrolysis can be easily controlled by the reaction temperature. ${ }^{27,28}$ Depending on the temperature, the hydrolysis of the ammonium carbonate and ammonium hydrogen carbonate occur at $\mathrm{pH}$ of approximately 9 . This is a very suitable condition to precipitate a large number of metal hydroxides. ${ }^{29}$

Figure 1 shows the X-ray diffraction patterns of $\mathrm{Ni}^{2+} / \mathrm{Al}^{3+}$ and $\mathrm{Co}^{2+} / \mathrm{Al}^{3+} \mathrm{LDH}$, synthesized by the urea method (intercalated by carbonate anions), after chloride exchange reactions and with all LDH samples intercalated with the organic anions.

All patterns have typical profile of LDH structures and the diffraction peaks were indexed on a hexagonal system with rhombohedral symmetry (special group R-3m). ${ }^{30}$ The presence of the sharp basal reflection peaks related to the planes in the direction of the layers' stacking indicates good crystallinity. Since the $0 \mathrm{kl}$ diffraction peaks were broadened, the presence of layer stacking faults can be expected.

The basal distances of $\mathrm{LDH}$ containing $\mathrm{CO}_{3}{ }^{2-}$ and $\mathrm{Cl}^{-}$as counterion were calculated by Bragg's law with the peak of higher order possible (Table 1).

The values of the basal distances of LDH intercalated with organic ions were corrected according to the calculations described by Hermans et al. ${ }^{31}$ The basal distances calculated from Bragg's law for Ni/Al-LDH prepared by the synthesis of urea (carbonate intercalated) and ion exchange by chloride anions were 7.70 and $7.72 \AA$, respectively. The increase of the basal spacing by exchanging $\mathrm{CO}_{3}{ }^{2-}$ ions for the $\mathrm{Cl}^{\text {ions }}$ was also observed for Co/Al-LDH (Table 1), which attest the successful exchange reaction. ${ }^{32}$

The intercalations of organic anions (Figure 1) were also confirmed by the displacement of basal diffraction peaks towards smaller diffraction angles (Table 1). As expected, increasing the carbon number in the linear organic chain of the intercalated organic anion caused a corresponding increase in basal distances..$^{33}$ The maintenance of the 012 and 110 diffraction peaks is evidence that even after strong expansion of the basal distances, the original 3R polytype was preserved in the organophilic LDH.

The vibrational spectra in the infrared region for the samples of $\mathrm{Ni}^{2+} / \mathrm{Al}^{3+}$ and $\mathrm{Co}^{2+} / \mathrm{Al}^{3+} \mathrm{LDH}$ synthesized by 

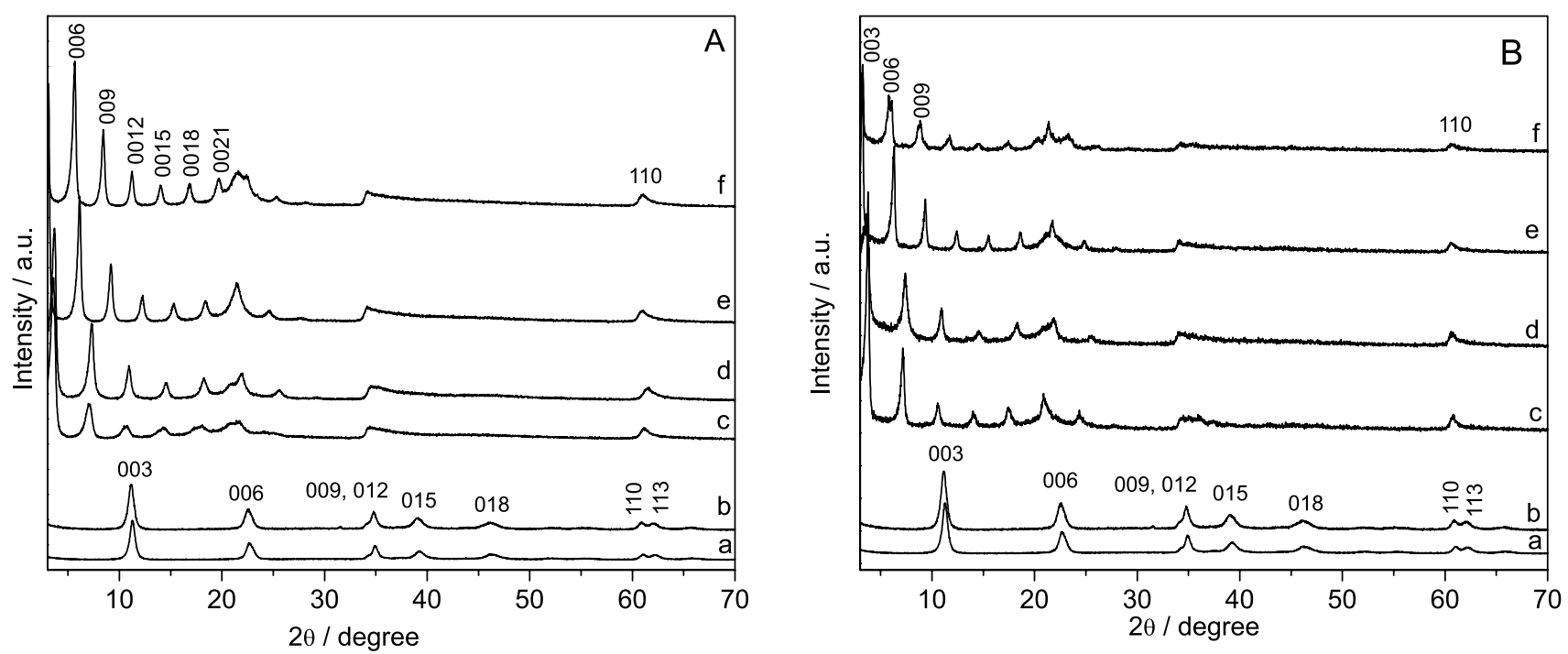

Figure 1. X-ray diffraction patterns of the samples. (A) NiU (a), NiUC (b), NiUD (c), NiUL (d), NiUP (e), NiUS (f); (B) CoU (a), CoUC (b), CoUD (c), CoUL (d), CoUP (e) and CoUS (f).

Table 1. Basal distances of the layered double hydroxides (LDHs)

\begin{tabular}{lccc}
\hline Sample & Intercalated ion & $\mathrm{n} ;(\mathrm{hkl})$ & Basal distance / $\AA$ \\
\hline NiU & carbonate & $3 ;(009)$ & $7.70^{*}$ \\
NiUC & chloride & $3 ;(009)$ & $7.72^{*}$ \\
NiUD & dodecylsulfate & 1 to $5 ;(003)$ to $(0015)$ & $24.90^{* *}$ \\
NiUL & laurate & 1 to $5 ;(003)$ to $(0015)$ & $24.37^{* *}$ \\
NiUP & palmitate & 1 to $5 ;(003)$ to $(0015)$ & $28.86^{* *}$ \\
NiUS & stearate & 1 to $5 ;(003)$ to $(0015)$ & $31.74^{* *}$ \\
CoU & carbonate & $3 ;(009)$ & $7.78^{*}$ \\
CoUC & chloride & $3 ;(009)$ & $7.82^{*}$ \\
CoUD & dodecylsulfate & 1 to $5 ;(003)$ to $(0015)$ & $25.90^{* *}$ \\
CoUL & laurate & 1 to $5 ;(003)$ to $(0015)$ & $24.02^{* *}$ \\
CoUP & palmitate & 1 to $5 ;(003)$ to $(0015)$ & $28.88^{* *}$ \\
CoUS & stearate & 1 to $5 ;(003)$ to $(0015)$ & $30.88^{* *}$ \\
\hline
\end{tabular}

*Calculated with Bragg's law: $\mathrm{d}=\mathrm{n} \lambda / 2 \operatorname{sen} \theta$, with $\lambda=1.5418 \AA$; **alculated according to the procedure described in the literature. ${ }^{31}$

the urea method are shown in Figure 2, where a broad absorption band near $3457 \mathrm{~cm}^{-1}$ can be observed, assigned to the $\mathrm{O}-\mathrm{H}$ vibration of the hydroxyl groups of the layers and the intercalated or sorbed water molecules of LDH.

In the $1630 \mathrm{~cm}^{-1}$ region, the bands can be associated with the angular deformation of the water molecules. Absorptions in the regions of 1380 and $820 \mathrm{~cm}^{-1}$ are related to the symmetric stretching modes $v_{2}$ and $v_{3}$, respectively, of the $\mathrm{C}-\mathrm{O}$ bond of the carbonate anions intercalated in $\mathrm{NiU}$ and $\mathrm{CoU}$. In the $1380 \mathrm{~cm}^{-1}$ region, bands attributed to the $\mathrm{C}-\mathrm{O}$ stretching of the carbonate anion had the lowest intensity and the band in the region of $820 \mathrm{~cm}^{-1}$ disappeared in the case of NiUC and CoUC. Thus, the success of ion exchange of $\mathrm{CO}_{3}^{2-}$ ions by $\mathrm{Cl}^{-}$ions was confirmed. The bands in the region of $680-600 \mathrm{~cm}^{-1}$ were attributed to the translational mode of the $\mathrm{Al}-\mathrm{OH}$ bond, being characteristic of the LDH layers.

The vibrational spectra in the infrared region for $\mathrm{Ni}^{2+} / \mathrm{Al}^{3+}$ and $\mathrm{Co}^{2+} / \mathrm{Al}^{3+} \mathrm{LDH}$ intercalated with dodecylsulfate, laurate, palmitate and stearate anions showed a broad band in the region of $3584-3586 \mathrm{~cm}^{-1}$, generally attributed to the vibrations of $\mathrm{O}-\mathrm{H}$ bonds of hydroxyl groups from LDH layers. The spectra of all products showed common bands at 729 and $620 \mathrm{~cm}^{-1}$, which can be attributed to vibrations of $\mathrm{M}-\mathrm{O}$ bonds of the layered compound (where $\mathrm{M}=\mathrm{M}^{+2}$ and/or $\mathrm{M}^{+3}$ ). Bands were also observed in the region of $3509-3454 \mathrm{~cm}^{-1}$ and $1632-1634 \mathrm{~cm}^{-1}$, attributed respectively to the $\mathrm{O}-\mathrm{H}$ bonds from the LDH layers and intercalated water molecules. ${ }^{34}$

All organophilic LDH bands at 2920-2926 and $2846-2852 \mathrm{~cm}^{-1}$ are related to the $\mathrm{C}-\mathrm{H}$ axial deformation of the $\mathrm{CH}_{2}$ and $\mathrm{CH}_{3}$ groups, respectively, and from 1456 to $1467 \mathrm{~cm}^{-1}$ and 1410 to $1413 \mathrm{~cm}^{-1}$ to asymmetric angular and symmetrical deformation vibrations of the methyl, respectively, from the organic chain. For LDH intercalated with the surfactantDDS, characteristic bands of the vibrational modes of S-O bonds of the sulfate group were observed at $1213-1229,1051-1064,984-986$ and $830-825 \mathrm{~cm}^{-1} .^{16}$

For LDH intercalated with anions containing a carboxylate group, the characteristic bands of asymmetric and symmetric stretching of $\mathrm{C}-\mathrm{O}$ bonds were observed at $1550-1548 \mathrm{~cm}^{-1}$ and $1410-1413 \mathrm{~cm}^{-1}$, respectively. ${ }^{33}$ These results demonstrate the successful intercalation of organic anions in the $\mathrm{Ni}$ and Co LDH. All bands attributions of the respective samples are shown in Table S1 (Supplementary Information).

The thermal analysis curves of LDH intercalated with $\mathrm{CO}_{3}{ }^{2-}, \mathrm{Cl}^{-}$and with organic anions are shown, respectively, 

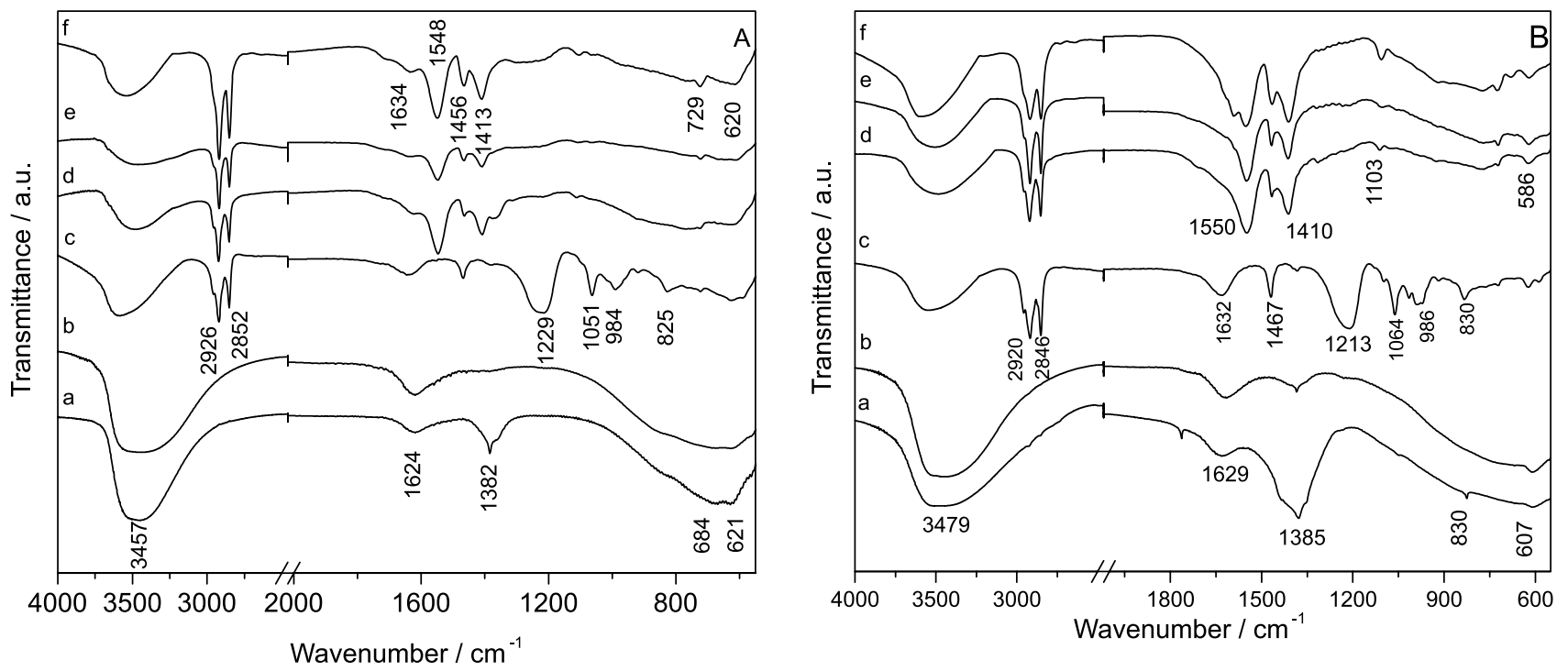

Figure 2. Fourier transform infrared spectra for the samples. (A) NiU (a), NiUC (b), NiUD (c), NiUL (d), NiUP (e), NiUS (f); (B) CoU (a), CoUC (b), CoUD (c), CoUL (d), CoUP (e), CoUS (f).

in Figures 3A, 3B and 3C. A common DTG peak was observed at around $100{ }^{\circ} \mathrm{C}$ for all compounds, which is attributed to the removal of sorbed water molecules.

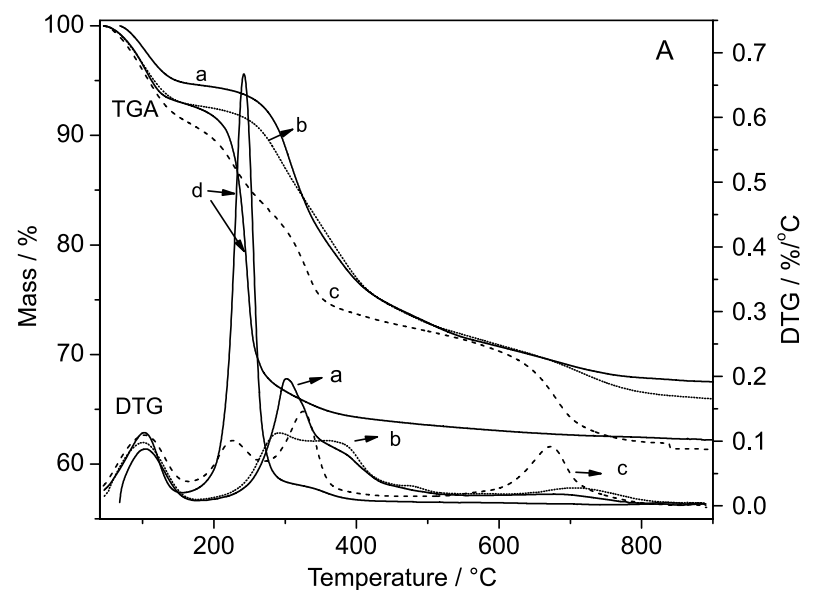

The TGA curve for the $\mathrm{LDH}$ intercalated with $\mathrm{CO}_{3}{ }^{2-}$ and $\mathrm{Cl}^{-}$presented three major mass losses. The first event, at up to $170{ }^{\circ} \mathrm{C}$, corresponds to the elimination of adsorbed

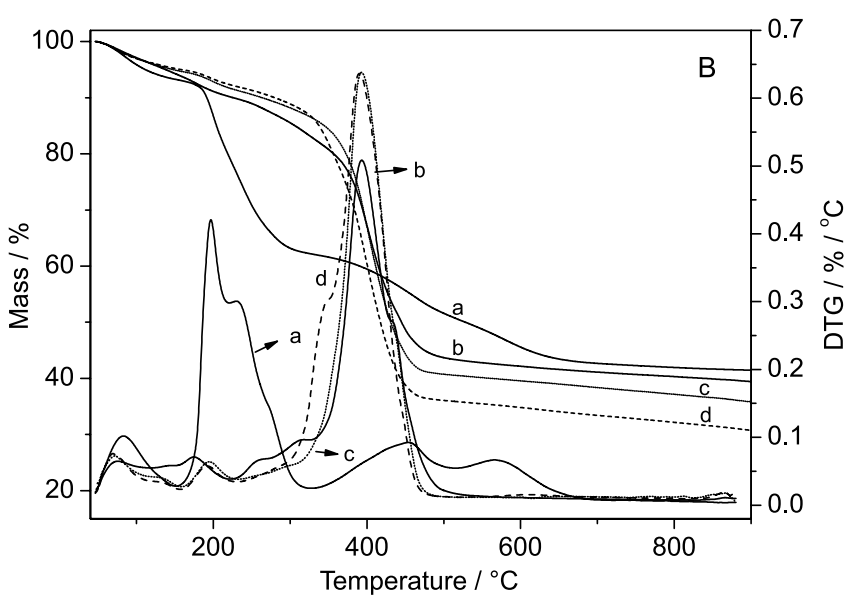

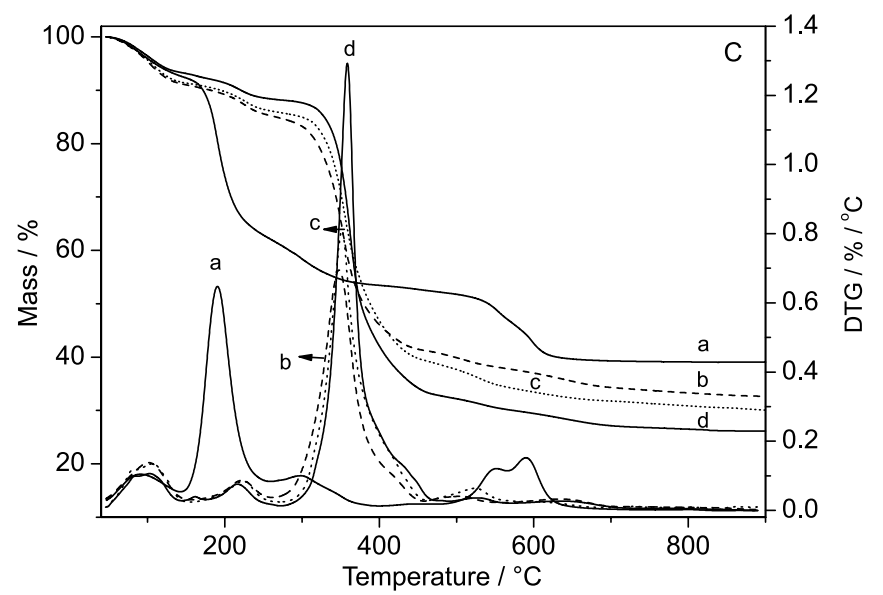

Figure 3. Thermal analysis curves (TGA/DTG) of (A) NiU (a), NiUC (b), CoU (c), CoUC (d); (B) NiUD (a), NiUL (b), NiUP (c), NiUS (d); and (C) CoUD (a), CoUL (b), CoUP (c), CoUS (d). 
and interlayer water molecules (mass losses of 5.3, 7.2, 9.2 and $7.3 \%$ for $\mathrm{NiU}, \mathrm{NiUC}, \mathrm{CoU}$ and $\mathrm{HCoC}$, respectively). The second mass loss up to $500{ }^{\circ} \mathrm{C}$ (mass losses of 27.1, 27.2, 27.9 and $36.4 \%$ for $\mathrm{NiU}, \mathrm{NiUC}, \mathrm{CoU}$ and $\mathrm{HCoC}$, respectively), is attributed to the loss of the interlayer $\mathrm{CO}_{3}^{2-}$ and $\mathrm{Cl}^{-}$ions and dehydroxylation of the LDH structure. ${ }^{35}$ The last mass loss up to $900{ }^{\circ} \mathrm{C}$, is attributed to the removal of the remaining carbonaceous material and formation of metal oxides (mass losses of 32.5, 34.1, 38.6 and $37.8 \%$ for $\mathrm{NiU}, \mathrm{NiUC}, \mathrm{CoU}$ and $\mathrm{HCoC}$, respectively). ${ }^{36-40} \mathrm{NiU}$ is more stable than the other two compounds, presenting two DTG peaks at 308 and $383{ }^{\circ} \mathrm{C}$ while the peaks were observed at 291, 381 and $721^{\circ} \mathrm{C}$ for NiUC, 230, 330 and $678{ }^{\circ} \mathrm{C}$ for $\mathrm{CoU}$ and at $242{ }^{\circ} \mathrm{C}$ for CoUC.

The thermal decomposition behavior for all LDHs intercalated with organic anions was more complex than those intercalated with carbonate and chloride anions (Figures 3B and 3C). As expected, NiUD and CoUD behave completely different from the intercalated carboxylates, being decomposed earlier with at least four mass losses (NiUD: $6.7 \%$ up to $150{ }^{\circ} \mathrm{C}, 38.7 \%$ up to $360^{\circ} \mathrm{C}$ and $58.5 \%$ up to $900{ }^{\circ} \mathrm{C}$ (DTG peaks at $83,198,229,453$ and $567^{\circ} \mathrm{C}$ ); CoUD: $7.7 \%$ up to $150{ }^{\circ} \mathrm{C}, 45.8 \%$ up to $360^{\circ} \mathrm{C}$ and $60.9 \%$ up to $900{ }^{\circ} \mathrm{C}$ (DTG peaks at $190,298,550$ and $590^{\circ} \mathrm{C}$ )). The TGA curves for the Ni/Al and Co/Al-LDH intercalated with carboxylates have a similar behavior, with the final mass losses proportional to the carbonic chain length. For the nickel derivatives, the first event up to $150{ }^{\circ} \mathrm{C}$ corresponds to the elimination of sorbed and interlayer water molecules (mass losses of 5.7, 5.1 and 4.8\% for NiUL, NiUP and NiUS, respectively).

The second mass loss up to $900{ }^{\circ} \mathrm{C}$ (mass losses of 60.5, 64.1 and $69.3 \%$ for NiUL, NiUP and NiUS, respectively) is attributed to the dehydroxylation of the LDH structure, carbonization of all organic molecules and formation of the respective metal oxides. DTG peaks were observed at 74 , 180 and $401{ }^{\circ} \mathrm{C}$ for NiUL; 72,200 and $401{ }^{\circ} \mathrm{C}$ for NiUP; and $72,193,356$ and $401{ }^{\circ} \mathrm{C}$ for NiUS.

In the TGA curves for the $\mathrm{Co} / \mathrm{Al}-\mathrm{LDH}$ derivatives, the first mass loss up to $150{ }^{\circ} \mathrm{C}$, was $8.0 \%$ for CoUL, $8.6 \%$ for CoUP and $6.9 \%$ for CoUS, and the second mass loss, up to $900{ }^{\circ} \mathrm{C}$, was of $67.3 \%$ for CoUL, $69.9 \%$ for CoUP and $73.8 \%$ for CoUS, attributed to the dehydroxylation of the LDH structure, carbonization of all organic molecules and formation of metal oxides. DTG peaks were observed at 226 and $351^{\circ} \mathrm{C}$ for CoUL; 224, 356 and $526^{\circ} \mathrm{C}$ for NiUP; and 221 and $360^{\circ} \mathrm{C}$ for CoUS. The temperature for dehydration of the organically modified LDH is lower than for the non-modified LDH. This occurs because the interaction of water molecules is reduced due to the incorporation of organophilic anions. ${ }^{37}$
Figure 4 and Table S2 (Supplementary Information) shows the results for Young's modulus of nanocomposites containing Ni/Al LDH intercalated with dodecylsulfate, laurate, palmitate and stearate (NiUD, NiUL, NiUP and NiUS).

In general, the modulus decreased with the addition of all fillers for all nanocomposites. These results suggest, as reported by Tang et al.., ${ }^{41}$ some agglomeration of the filler in the polymer matrix, resulting in lower Young's modulus of the nanocomposites. In general, the addition of all the fillers caused a small increase or maintenance of the tensile strength values of the nanocomposites, as seen in Figure 4 and Table S2 (Supplementary Information). During tensile testing, the occurrence of flow shear bands was noted at the maximum stress. Shear bands are thin planar regions of high shear deformation. They start in regions where there is little heterogeneity in deformation due to internal or surface imperfections, or concentration of stress. ${ }^{42,43}$ Shear bands occur in dimensions much larger than the sizes of LDH crystals. Thus, the addition of LDH intercalated with organic anions as filler contributed to the homogeneity of deformation and displacement of the flow plains by interrupting the development of shear bands, and this phenomenon affected the nanocomposite tensile strength results. In general (Figure 4, Table S2), the increase of the carbon chains of intercalated surfactants in LDH caused an increase in the elongation values at high loading levels. The organic chains intercalated in LDH have affinity for the polymer, with a lubrication effect. This facilitated the flow of the polymer chains during the tensile test. Higher ductility values for the polymer materials are beneficial, especially for absorbing shock impacts. ${ }^{41}$ However, the addition of 7\% LDH intercalated with stearate ions caused an increase of approximately $300 \%$ in the elongation value, while adding 7\% LDH intercalated with dodecylsulfate decreased elongation by $10 \%$ compared to the pure polymer, thus indicating that the lubricating effect strongly depends on the type of intercalated anions and LDH composition. As the results for the sample NiUS were unusual and distinct from CoUS, the NiUS samples were prepared independently 5 times and the elongation was reproducible.

The nanocomposite containing LDH intercalated with stearate showed slightly higher values than the pure polymer for ductility and little change in tensile strength and Young's modulus. This indicates good interaction of filler with the matrix, resulting in increased ductility of the nanocomposites. Similar results were also obtained by Yang et $\mathrm{al} .{ }^{44}$ The results for Young's modulus and LDPE nanocomposites with addition of $\mathrm{Co} / \mathrm{Al}-\mathrm{LDH}$ intercalated with dodecylsulfate, laurate, palmitate and stearate are summarized in Table S3 and Figure S1 (Supplementary Information). 

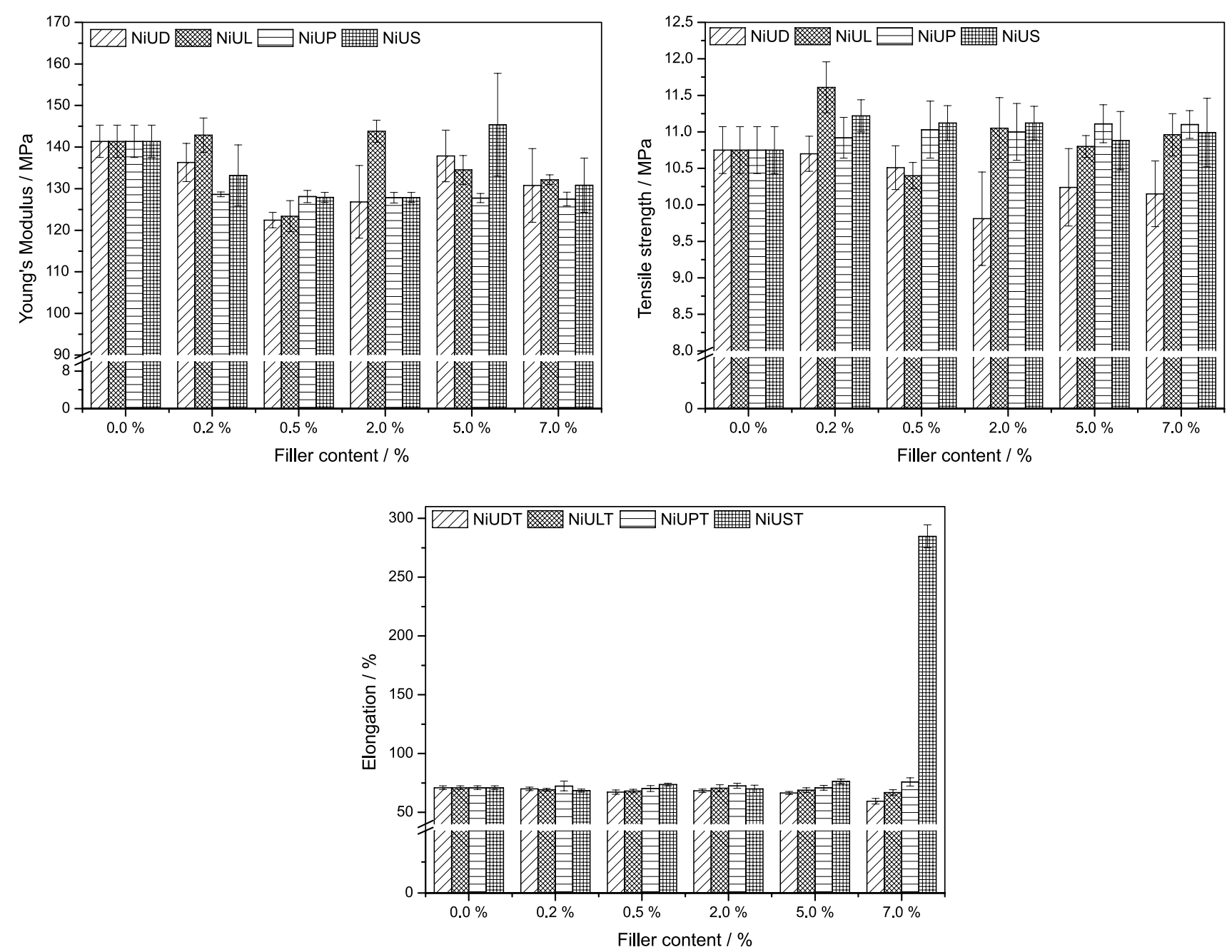

Figure 4. Mechanical properties to LDPE composites containing Ni/Al LDHs intercalated with dodecylsulfate, laurate, palmitate and stearate anions.

The increase in the number of carbons of the organic molecules intercalated in the LDH led only to small changes in modulus. Furthermore, with increasing loading of CoUD, CoUL and CoUP, the Young's modulus values remained practically constant. These results can be explained by a poor dispersion of filler in the polymer matrix. ${ }^{44}$ Results for heating/cooling experiments obtained by DSC measurements for LDPE nanocomposites containing organophilic Ni/Al LDH (Figure 5) showed one exothermic peak during the first cooling and one main endothermic peak during the second heating, beyond small peaks indicated by asterisks. As the samples were treated at $150{ }^{\circ} \mathrm{C}$ before registering the curves, it is expected that the humidity is removed and the observed signals are only for the polymer melting and crystallization, attributed to LDPE relaxation. In fact, the first heating is conducted to eliminate thermal history of the nanocomposites. Different melting and crystallization enthalpy values were observed (Figure 5), indicating that the events are not totally reversible but the Ni/Al-LDH filler seems not to influence significantly the LDPE melting/crystallization temperatures and not even the level of crystallization. Only in the case of NiUS (Figure 5B, curve e), the enthalpy is significantly smaller than in neat LDPE, indicating the crystallinity reduction.

Differential scanning calorimetric (DSC) results for some LDPE nanocomposite heating containing organic $\mathrm{Co} / \mathrm{Al} \mathrm{LDH}$ (Figure 6A) showed also the relaxation peak at about $50{ }^{\circ} \mathrm{C}$ (indicated by $*$ in Figure 6B) and one main peak of melting at around $103{ }^{\circ} \mathrm{C}$ and at least one peak at higher temperature, which depends on the intercalated specie.

Especially in the first cooling curves of CoUP (Figure 6B, curve d) and CoUS (Figure 6B, curve e), the presence of a second and third peak of crystallization, that occurs at higher temperatures, indicate that these crystalline domains are more abundant than in the other samples. This domains formation is induced by the CoUP and CoUS fillers. Melting and crystallization enthalpy quantifications were difficult to obtain in the case of $\mathrm{Co} / \mathrm{Al}$ derivatives due to the coalescence of several peaks. 

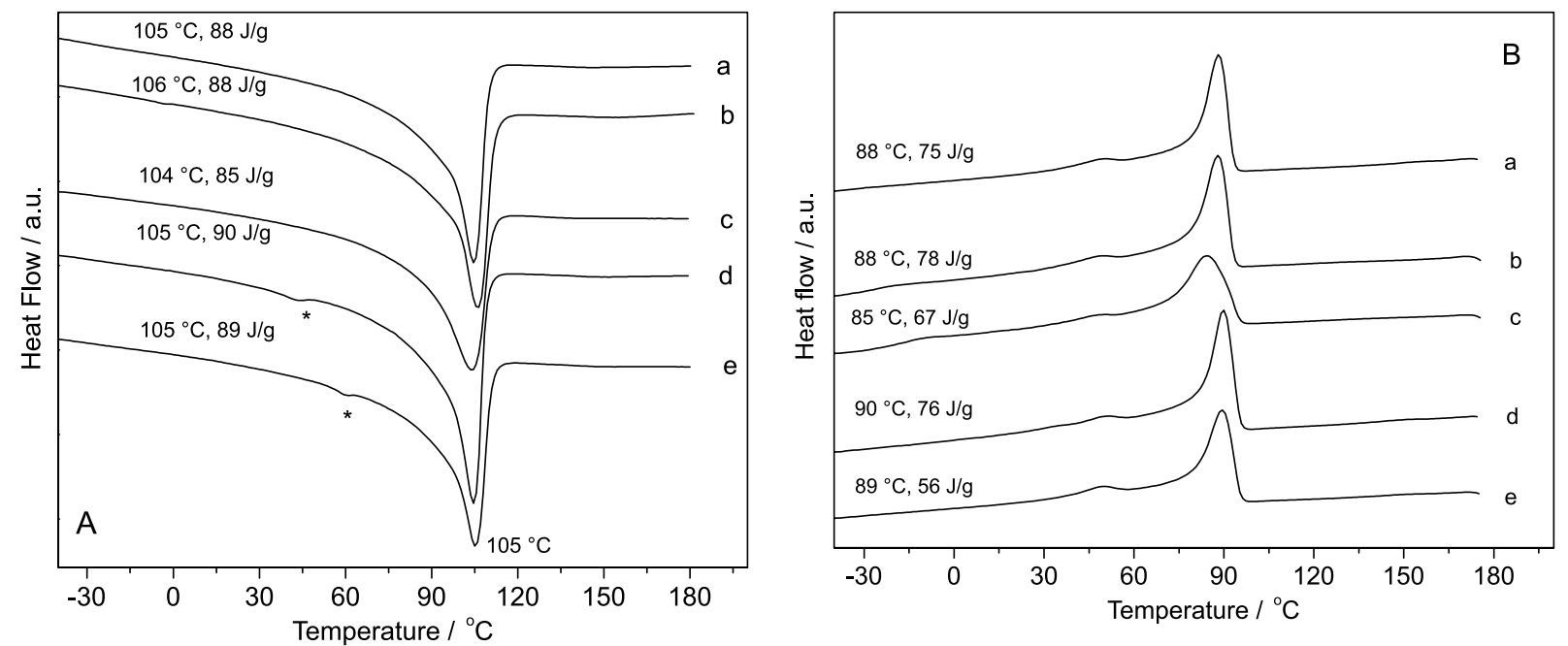

Figure 5. DSC curves for the neat LDPE (a) and nanocomposites containing 7\% of the filler: NiUD (b), NiUL (c), NiUP (d), NiUS (e). (A) Second heating; (B) first cooling. *LDPE relaxation.
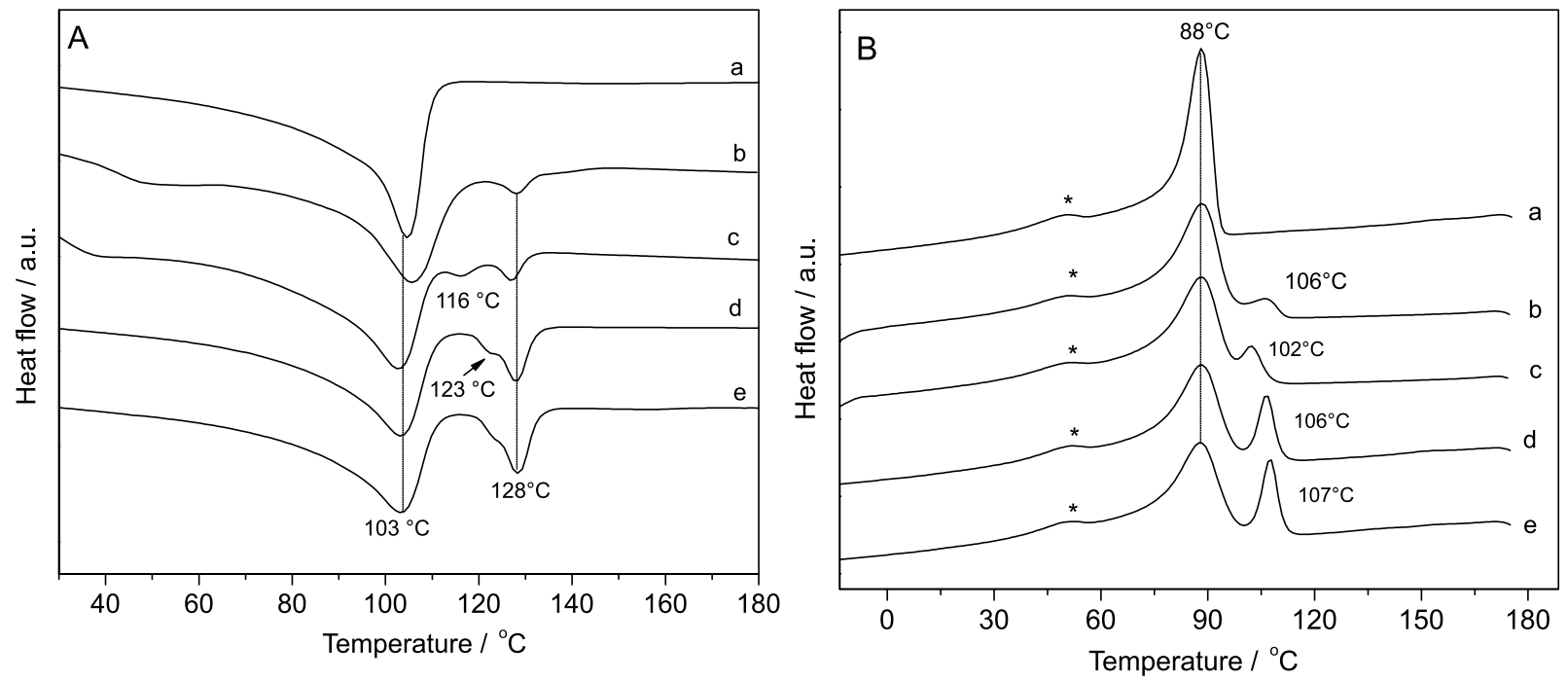

Figure 6. DSC curves for the neat LDPE (a) and nanocomposites containing 7\% of the filler: CoUD (b), CoUL (c), CoUP (d), CoUS (e). (A) Second heating; (B) first cooling. *LDPE relaxation.

Plastic deformation in shear zones or cracks, which are precursors of the stage fracture in semi-crystalline polymers like LDPE are better analyzed when the fracture of the polymer is performed cryogenically. SEM images of LDPE nanocomposites containing organophilic Co/Al LDH and Ni/Al LDH are shown in Figure 7.

Although only low magnification images could be obtained due to the charging during analysis, all samples present good dispersion of the fillers on polymer matrix. Strangely, the SEM images of LDPE nanocomposite containing $\mathrm{Ni} / \mathrm{Al} \mathrm{LDH}$ show formation of larger agglomeration of the filler embedded into the polymer (Figures 7c-7e), which behave like a big particle, which are segregated and loosely bound to the polymeric matrix. These particles were sometimes detached from the polymeric matrix during cryogenic fracture as observed in Figure 7c, leaving big depressions. As these particles are observed in the Co/Al-LDH samples, we suppose that could be attributed to those observed in DSC high melting/ crystallization peaks (Figures 6A and 6B).

$\mathrm{X}$-ray diffraction patterns (Figure 8) of the nanocomposites containing 7\% of Ni/Al-LDH and $\mathrm{Co} / \mathrm{Al}-\mathrm{LDH}$ showed diffraction peaks at $21.5^{\circ}$ and $23.7^{\circ}$ (in 20) (indexed as 110, $d=4.15 \AA$; and 200, $d=3.76 \AA$ ), attributed to the crystalline domains of the neat LDPE. ${ }^{45}$

In the region of 2 to $4^{\circ}$ (in $2 \theta$ ) reflections of some organophilic LDH were observed, with the exception of NiUS and CoUS, where the absence of reflections suggests the delamination/exfoliation of the layered crystals in the LDPE matrix. The XRD patterns also showed an increase in interlayer distance for LDH intercalated with dodecylsulfate, laurate and palmitate 

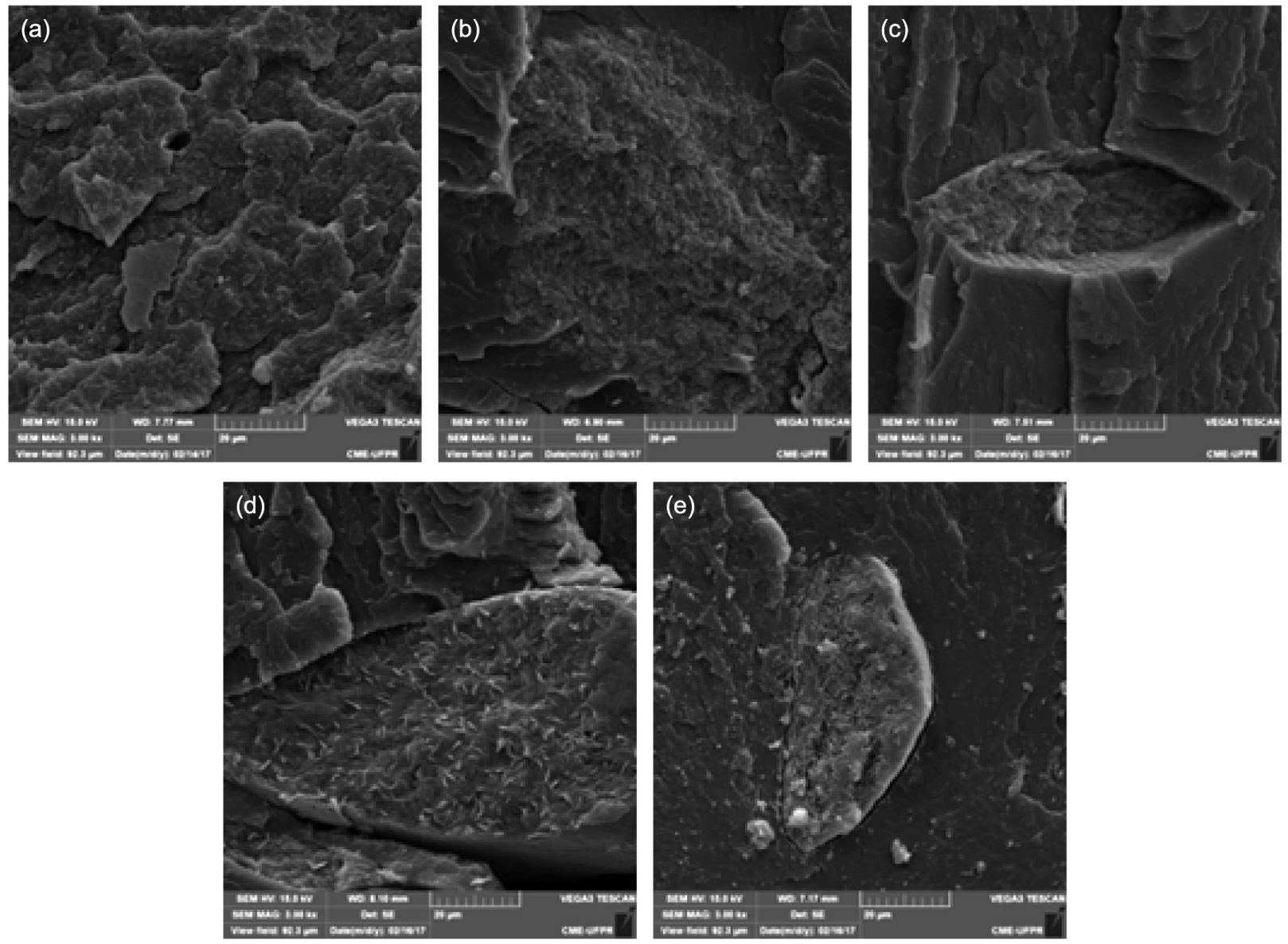

Figure 7. SEM images of cryogenic fracture for the LDPE nanocomposites containing 7\% of the fillers: NiUS (a), CoUD (b), PE-CoUL (c), PE-CoUP (d) and PE-CoUS (e).

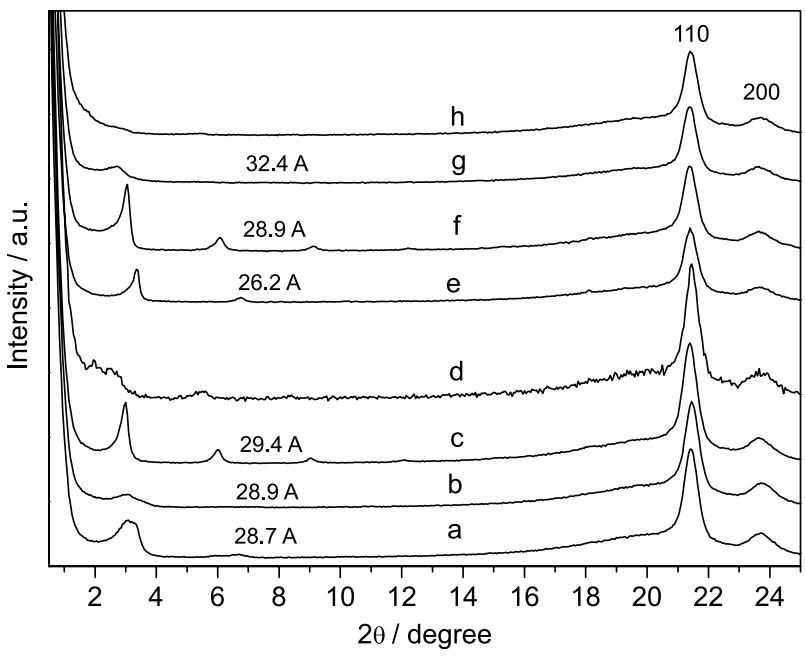

Figure 8. X-ray diffraction patterns of the nanocomposites containing $7 \%$ of NiUD (a), NiUL (b), NiUP (c), NiUS (d), CoUD (e), CoUL (f), CoUP (g), CoUS (h). 110, 200: indexed LDPE peaks.

in the nanocomposite compared to the neat organophilic LDH (compare Figure 8 with Table 1). Only in the case of NiUP and CoUL (Figures $8 \mathrm{c}$ and $8 \mathrm{f}$ ) planes attributed to the stacked layer (006), (009) were maintained when the organophilic LDH was added, although the basal distances were slightly larger.

It can be concluded that during the extrusion process, where no shear forces were applied, long polymer chains interacted with organic anions intercalated in the LDH due to high affinity, causing expansion, delamination/exfoliation of the layered crystals in the polymer matrix. Nanocomposites containing LDH intercalated with carboxylic anions presented better results for exfoliation/delamination. Usually sulfonate and carboxylate surfactants form micelles with varying sizes of nonpolar tails and polar heads. The formation of micelles in surfactants with different chain sizes intercalated with these organic anions causes the difference in delamination/exfoliation efficiency. ${ }^{46}$

Thermal analyses curves (TGA/DTG) of LDPE nanocomposite containing $\mathrm{Ni} / \mathrm{Al}-\mathrm{LDH}$ and $\mathrm{Co} / \mathrm{Al}-\mathrm{LDH}$ are shown in Figures 9A and 9B, respectively.

The mass loss between room temperature and $300{ }^{\circ} \mathrm{C}$, corresponding to water removal, was less than $5 \%$. The thermal decomposition stage associated with temperatures in the range $300-600{ }^{\circ} \mathrm{C}$ (with a weight loss of more than $90 \%$ ) was attributed to pyrolytic decomposition of 

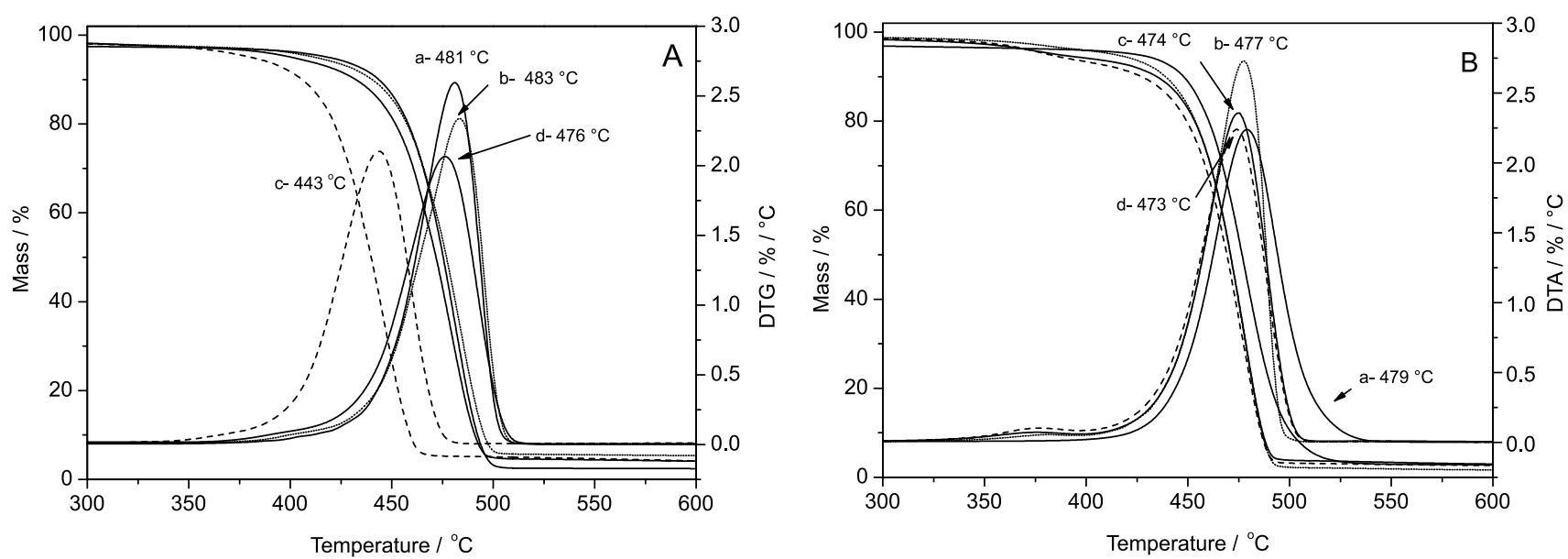

Figure 9. Thermal analysis curves (TGA/DTG) of LDPE nanocomposites containing 7\% of filler. (A) NiUD (a), NiUL (b), NiUP (c), NiUS (d); (B) CoUD (a), CoUL (b), CoUP (c), CoUS (d).

the LDPE. ${ }^{38}$ For nickel derivatives, the DTG peak of the nanocomposite containing NiUP occurs at around $443{ }^{\circ} \mathrm{C}$ (Figure 9A, curve c), while the other nanocomposites containing LDH intercalated with CoUD, CoUL or CoUS the peak is observed at around $480{ }^{\circ} \mathrm{C}$. On the other hand, the thermal decomposition of nanocomposites containing $\mathrm{Co} / \mathrm{Al} \mathrm{LDH}$ intercalated with organic molecules remained nearly constant.

As observed, the hydrophobic and colored layered double hydroxides can be used as fillers, but small chemical or carbon chain lengths of the intercalated surfactant anions or the metals constituents of the layers as the $\mathrm{M}^{+2} / \mathrm{M}^{+3}$ molar ratios generate different behaviors. Colored LDH hydrophilic and hydrophobic matrices are great potential to be used as functional fillers to produce polymer nanocomposites with on demand design properties.

\section{Conclusions}

Green Ni/Al and pink Co/Al-LDH were successfully synthesized as pure phases through a simple method using inexpensive materials, which showed promising use as fillers in nanocomposites, especially due to the characteristic of attributing color to the polymer.

The XRD and FTIR data are consistent with the intercalation of carbonate into the material produced with urea hydrolysis, where the carbonate anions were replaced by hydrated chloride anions and subsequently substituted by organophilic organic anions, namely dodecylsulfate, laurate, palmitate and stearate. The characterized organophilic materials were used as fillers in LDPE, and homogeneous and colored nanocomposites were obtained.

Fillers added to LDPE with concentrations of 0.2, 0.5, 2 and 5\% presented, in general, maintenance of Young's modulus and tensile strength, tending to the reduction with high loading. Most of the nanocomposites presented similar elongations, although NiUS stood out, with an elongation increase of $300 \%$, with small standard deviation for 5 assayed samples prepared using different batches.

DSC indicated the effect of the Co/Al-LDH in inducing the formation of LDPE crystalline domains, especially at higher temperature than neat LDPE. This effect was not observed for the Ni/Al-LDH. SEM images of cryogenic fractures indicated that in general, a good dispersion of the filler occurs in the LDPE matrix. In spite of that, in some regions segregation of $\mathrm{LDH}$ were observed, indicating a poor interaction with the polymer.

Overall the results show that the performance of nanocomposites depends on several factors, including organo-modification of LDH and layers metal composition, and colored nanocomposites can be obtained by choosing the correct combination of $\mathrm{M}^{+2} / \mathrm{M}^{+3}$ metals in the $\mathrm{LDH}$ filler, opening a new venue to produce colored polymer composites to replace the conventional polymer containing the exudable dye salts.

\section{Supplementary Information}

Supplementary information (tabulated FTIR absorption bands attribution, tabulated mechanical properties to LDPE nanocomposites containing $\mathrm{Ni} / \mathrm{Al} \mathrm{LDHs}$ and $\mathrm{Co} / \mathrm{Al} \mathrm{LDH}$ and bar graphics comparing the mechanical properties to LDPE) is available free of charge at http://jbcs.sbq.org.br as PDF file.

\section{Acknowledgments}

The authors thank Conselho Nacional de Desenvolvimento Científico e Tecnológico (CNPq), Coordenação de Aperfeiçoamento de Pessoal de Nível Superior (CAPES), 
Financiadora de Estudos e Projetos (FINEP) and Universidade Federal do Paraná (UFPR) for financial support. S. J. also thanks CNPq - Ciências sem Fronteiras for the PhD grant in the Leibniz-Institut für Polymerforschung Dresden, Germany, where part of this work was developed.

\section{References}

1. Shu, Y.; Yin, P.; Wang, J.; Liang, B.; Wang, H.; Guo, L.; Ind. Eng. Chem. Res. 2014, 53, 3820.

2. Kojima, Y.; Usuki, A.; Kawasumi, M.; Okada, A.; Kurauchi, T.; Kamigaito, O.; J. Polym. Sci., Part A: Polym. Chem. 1993, 31, 1755.

3. Kojima, T.; Usuki, A.; Kawasumi, M.; Okada, A.; Kurauchi, T.; Kamigaito, O.; J. Mater. Res. 1993, 5, 1180.

4. Usuki, A.; Kojima, Y.; Kawasumi, M.; Okada, A.; Fukushima, Y.; Kurauchi, T.; Kamigaito, O.; J. Mater. Res. 1993, 8, 1179.

5. Kalaprasad, G.; Francis, B.; Thomas, S.; Radhesh, K. C.; Pavithran, C.; Groenickx, G.; Thomas, S.; Polym. Int. 2004, 53, 1624.

6. Malucelli, G.; Palmero, P.; Ronchetti, S.; Delmastro, A.; Montanaro, L.; Polym. Int. 2010, 59, 1084.

7. Chrissafis, K.; Bikiaris, D.; Thermochim. Acta 2011, 523, 1.

8. Arizaga, G. G. C.; Satyanarayana, K. G.; Wypych, F.; Solid State Ionics 2007, 158, 1143.

9. Peng, H.; Tjiu, W. C.; Shen, L.; Huang, S.; He, C.; Liu, T.; Compos. Sci. Technol. 2009, 69, 991.

10. Coiai, S.; Passaglia, E.; Hermann, A.; Augier, S.; Pratelli, D.; Streller, R. C.; Polym. Compos. 2010, 31, 744.

11. Gu, Z.; Liu, W.; Dou, W.; Tang, F.; Polym. Compos. 2010, 31, 928.

12. Tai, Q.; Chen, L.; Song, L.; Hu, Y.; Yuen, R. K. K.; Polym. Compos. 2011, 32, 168.

13. Penco, M.; Spagnoli, G.; Rahman, M. A.; Passaglia, E.; Coiai, S.; Ciardelli, F.; Polym. Compos. 2011, 32, 986.

14. Barik, S.; Kisku, S. K.; Behera, L.; Swain, S. K.; Polym. Compos. 2015, 36, 2140.

15. Zhang, S.; Liu, X.; Gu, X.; Jiang, P.; Sun, J.; Polym. Compos. 2015, 36, 2230.

16. Costa, F. R.; Abdel-Goad, M.; Wagenkencht, U.; Heinrich, G.; Polymer 2005, 46, 4447.

17. Nakagaki, S.; Mantovani, K. M.; Machado, G. S.; Castro, K. A. D.; Wypych, F.; Molecules 2016, 21, 1.

18. Forano, C.; Hibino, T.; Leroux, F.; Taviot-Guého, C. In Layered Double Hydroxide; Bergaya, F.; Lagaly, G., eds.; Elsevier Science Developments in Clay Science: Amsterdam, 2006, ch. 13.1.

19. Kameda, T.; Saito, M.; Umetsu, Y.; Mater. Trans. 2006, 47, 923.

20. Wang, H.; Zheng, C.; Li, F.; Chem. Eng. J. 2010, 158, 633.

21. Jaerger, S.; Zawadzki, S. F.; Wypych, F.; Amico, S. C.; Polímeros 2014, 24, 673.
22. Zimmermann, A.; Jaerger, S.; Zawadzki, S. F.; Wypych, F.; J. Polym. Res. 2013, 20, 224.

23. Marangoni, R.; Ramos, L. P.; Wypych, F.; J. Colloid Interface Sci. 2009, 330, 303.

24. Marangoni, R.; Mikowski, A.; Wypych, F.; J. Colloid Interface Sci. 2010, 351, 384.

25. Hibino, T.; Eur. J. Inorg. Chem. 2014, 31, 5311.

26. Iyi, N.; Tamura, K.; Yamada, H.; J. Colloid Interface Sci. 2009 , $340,67$.

27. Ma, R.; Sasaki, T. In Nanosheets and Nanocones Derived from Layered Double Hydroxide; Chen, Y. I., ed.; CRC Taylor \& Francis Group: New York, 2015, ch. 5.

28. Shaw, W. H. R.; Bordeaux, J. J.; J. Am. Chem. Soc. 1995, 77, 4729 .

29. Costantino, U.; Marmottini, F.; Nocchetti, M.; Vivani, R.; Eur. J. Inorg. Chem. 1998, 98, 1439.

30. Budhysutanto, W. N.; Cains, P. W.; van Rosmalen, G. M.; Kramer, H. J. M.; Appl. Clay Sci. 2012, 62-63, 27.

31. Hermans, J. J.; Keune, K.; von Loon, A.; Corkey, R. W.; Iedema, P. D.; Polyhedron 2014, 81, 335.

32. Takei, T.; Miura, A.; Kumada, N.; J. Asian Ceram. Soc. 2014, 2, 289.

33. Kutlu, B.; Meinl, J.; Leuteritz, A.; Brünig, H.; Heinrich, G.; Polymer 2013, 54, 5712.

34. Rives, V.; Kannan, S.; J. Mater. Chem. 2000, 10, 489.

35. Herrero, M.; Labajos, F. M.; Rives, V.; Appl. Clay Sci. 2009, $42,5010$.

36. Kanezaki, E.; Mater. Res. Bull. 1998, 33, 773.

37. Costa, F. R.; Wagenknecht, U.; Heinrich, G.; Polym. Degrad. Stab. 2007, 92, 1813.

38. Musking, N.; Magaraphan, R.; Coiai, S.; Passaglia, E.; eXPRESS Polym. Lett. 2011, 5, 428.

39. Costa, F. R.; Leuteritz, A.; Wagenknecht, U.; Jehnichen, D.; Häußler, L.; Heinrich, G.; Appl. Clay Sci. 2008, 38, 153.

40. Constantino, V. R. L.; Pinnavaia, T. J.; Inorg. Chem. 1995, 34 , 883.

41. Tang, Y.; Xia, X.; Wang, Y.; Xie, C.; Contraception 2011, 83, 255.

42. Hotta, S.; Paul, D. R.; Polymer 2004, 45, 7639.

43. Wang, L.; Li, B.; Cao, J.; Appl. Clay Sci. 2013, 72, 138.

44. Yang, J.; Li, X.; Liu, C.; Rui, E.; Wang, L.; Nucl. Instrum. Methods Phys. Res. 2015, 365, 55.

45. Panaitescu, D. M.; Frone, A. N.; Radovici, C.; Nicolae, C.; Perrin, F. X.; Polym. Int. 2014, 63, 228.

46. Kutlu, B.; Leuteritz, A.; Boldt, R.; Jehnichen, D.; Heinrich, G.; Chem. Eng. J. 2014, 243, 394.

Submitted: March 30, 2017 Published online: May 25, 2017 